Pierre A. Casthely MD, Steven Landesman MD, Phillip N. Fyman MD, M. Arisan Ergin MD, Randall Griepp MD, Gerald L. Wolf MD

\title{
Retrograde intubation in patients undergoing open heart surgery
}

Cardiovascular changes during difficult intubation were studied in 25 patients undergoing open heart surgery. The study was divided into two phases. Phase A from the first laryngoscopy to the fourth unsuccessful one; Phase $B$ from a stabilization period until after retrograde intuba. tion was performed. During phase $A$, heart rate (HR) increased significantly from $75 \pm 6.5$ beats $m$ min before laryngoscopy to $95 \pm 8.5(p<0.05)$ after the last laryngoscopy. Mean arterial pressure (MAP) also increased from $82.5 \pm 4.75 \mathrm{mmHg}$ to $105 \pm 5.15(p<0.005)$ after the last laryngoscopy. Cardiac index $(\mathrm{CI})$ decreased from $2.9 \pm 0.3 \mathrm{~L} \cdot \mathrm{min}^{-1} \cdot \mathrm{m}^{-2}$ before to $2.55 \pm 0.2$ after the last laryngoscopy. Pulmonary capillary wedge pressure (PCWP) increased from $10.5 \pm 1 \mathrm{mmHg}$ before to 19.25 $\pm 1.5(p<0.01)$ after the last laryngoscopy.

No statistically significant changes in $H R, M A P, C l$, and PCWP occurred before and after intubation during Phase $B$. Three patients had elevated ST segments during Phase $A$ which responded to IV nitroglycerin and propranolol. None was detected during Phase B. There were more lacerated lips and teeth damaged during Phase $A$. One patient developed a small peritracheal haematoma after the retrograde intubation, for which no treatment was required. This technique is safe and produces minimal cardiovascular changes for difficult intubation in patients undergoing open heart surgery.

\section{Key words}

INTUBATION, ENDOTRACHEAL: techniques, retrograde, cardiovascular effects.

From the Departments of Anesthesiology and Surgery, State University Hospital, Downstate Medical Center, New York.

Address correspondence to: Dr. P.A. Casthely, Department of Anesthesiology, State University Hospital, Downstate Medical Center, 450 Clarkson Avenue, Box 6, Brooklyn, New York 11203.
The placement of a tracheal guide to facilitate tracheal tube insertion when tracheal intubation is difficult is a useful technique bridging the gap between a failed direct laryngoscopy - intubation attempt and surgical access to the airway (i.e., tracheostomy). Antegrade guides, such as flexible fiberoptic laryngoscopes, though appropriate in many clinical situations, have limitations, and retrograde guide insertion may be thus indicated.

We report a series of open heart surgery patients who were intubated using a transcricothyroid membrane retrograde guide and were then anticoagulated for cartiopulmonary bypass (CPB).

\section{Methods}

From June 1980 through December 1984 in a population of 2000 open heart cases, twenty-five patients were technically difficult to intubate. Six had severe rheumatoid arthritis, one ankylosing spondylitis. The other patients had small mouths and "anterior larynx". The body mass index was not greater than 2.5; weights were $73 \mathrm{~kg}$ to $95 \mathrm{~kg}$; age range was $31-75$ years.

The surgical diagnoses were mixed: 18 patients scheduled for coronary artery bypass grafting (CABG), five for aortic valve replacement and two for mitral valve replacement.

A pulmonary arterial catheter and anterial line were routinely inserted prior to induction of anaesthesia. Preoperative medications consisted of morphine $0.1 \mathrm{mg} \cdot \mathrm{kg}^{-1}$ and atropine $0.4 \mathrm{mg}$ given one hour before surgery. All preoperative medications were continued up to the day of surgery. Induction consisted of fentanyl $25-30 \mu \mathrm{g} \cdot \mathrm{kg}^{-1}$, pancuronium $0.1 \mathrm{mg} \cdot \mathrm{kg}^{-1}$, and diazepam $10 \mathrm{mg}$, followed by laryngoscopy. Laryngoscopy was performed first using a Macintosh \#3 blade, initially followed by a Macintosh \#4 or Miller blade (Phase A).

After an average of four unsuccessful attempts, 
TABLE Haemodynamic data

\begin{tabular}{llcc}
\hline & $\begin{array}{l}\text { Before attempts (A) } \\
\text { Before intubation (B) }\end{array}$ & $\begin{array}{c}\text { After attempts }(A) \\
\text { After intubation }(B)\end{array}$ \\
\hline HR (beats/min) & (A) & $75 \pm 6.5$ & $95 \pm 8.5^{*}$ \\
& (B) & $80 \pm 5.0$ & $85 \pm 4.0$ \\
MAP (mmHg) & (A) & $82.5 \pm 4.8$ & $105 \pm 5.2^{*}$ \\
& (B) $70.5 \pm 5.0$ & $77.5 \pm 6.0$ \\
CI $\left(\mathrm{L} \cdot \mathrm{min}^{-1} \cdot \mathrm{m}^{-2}\right)$ & (A) $2.9 \pm 0.3$ & $2.55 \pm 0.2^{*}$ \\
& (B) $3.10 \pm 0.5$ & $3.20 \pm 1.5$ \\
PAP $\left(\mathrm{mmHg}^{2}\right)$ & (A) $18.75 \pm 1.8$ & $26.5 \pm 2.1^{*}$ \\
& (B) $20 \pm 1.8$ & $22.5 \pm 1.5$ \\
PCWP $(\mathrm{mmHg})$ & (A) $10.5 \pm 1.0$ & $19.25 \pm 1.5^{*}$ \\
& (B) $11.0 \pm 1.2$ & $13 \pm 1.0$ \\
CVP (mmHg) & (A) & $7 \pm 0.7$ & $8 \pm 0.5$ \\
& (B) $7.5 \pm 0.7$ & $7.5 \pm 0.5$ \\
\hline
\end{tabular}

*p $<0.05$, compared to "before attempts."

Phase A - multiple unsuccessful attempts to intubate oratly. Phase B - retrograde intubation.

using \#3, \#4 Macintosh blades and Miller blades, a retrograde intubation was performed using the following steps (Phase B): the neck was hyperextended by placing a roll of towels under the shoulder, prepping with betadine, and draping with sterile towels. The cricothyroid membrane was punctured with a 14-gauge needle and a 16-gauge 24-inch radiopaque catheter (intracatheter Deseret) was passed cephalad, via the trachea, into the oropharynx. While ventilation was still maintained by mask the wire was removed from the catheter. The catheter tip was pulled out of the mouth during direct laryngoscopy. The endotracheal tube was then threaded over the catheter into the trachea, while the catheter was held taut at both ends. Correct endotracheal position was confirmed by manually ventilating the patient and auscultating equal breath sounds bilaterally. The catheter was removed by cutting it at the puncture site, and pulling it through the endotracheal tube which was then advanced $2-3 \mathrm{~cm}$ further into the trachea. The endotracheal tube was then suctioned for blood and secretions. Compression dressings were applied at the puncture site for 24 hours. Heart rate, cardiac output (CO), central venous pressure (CVP), PCWP, pulmonary artery pressures (PAP), and MAP were measured before the first laryngoscopy, after the last unsuccessful laryngoscopy and before and after retrograde intubation. Fentanyl, halothane or isoflurane were given if needed to restore the eluated MAP to baseline values before performing the retrograde intubation.

Statistical analysis was done using a $t$ test for paired data and value of $p<0.05$ was considered significant.

\section{Results (Table)}

During Phase A, heart rate, mean arterial blood pressure, pulmonary artery pressure and pulmonary capillary wedge pressure all increase significantly from the observations before laryngoscopy to those after the last intubation attempt. No significant changes in these parameters were associated with retrograde intubation. Cardiac index decreased significantly during Phase $A$ but was unchanged during Phase B. No changes in CVP occurred during either phase. Halothane was given to control hypertension in three patients and isoflurane in four patients, during Phase A. Three patients during Phase A had elevated ST segments in the $V_{S}$ lead, which responded to nitroglycerin infusion and propranolol. No ST changes were detected during Phase B. The mean duration of Phase $A$ was $15.75 \pm 0.5$ minutes, phase B $3.5 \pm 0.02$ minutes. The average time for performing retrograde intubation was $\mathbf{4 5}$ seconds from the time of the cricothyroid membrane puncture to the insertion of the endotrachel tube. During Phase A five patients suffered lacerated lips, six teeth damage. One patient had an esophageal tear, which was diagnosed on the third postoperative day. During Phase B there was only one minor laceration of a lip. One patient who developed disseminated intravascular coagulopathy (DIC) intraoperatively had a $2 \times 2 \mathrm{~cm}$ peritracheal haematoma at the neck puncture site used to perform retrograde intubation, which resolved spontaneously after three days. No subcutaneous emphysema was seen in any patient.

\section{Discussion}

Standard anaesthetic management in patients having open heart surgery requires endotracheal intubation. Alternatives to intubation, such as regional anaesthesia or ventilation by mask, are not apropriate. When the larynx cannot be visualized, inability to intubate the patient may present a major obstacle to proceeding with the case. Various techniques have been developed to circumvent this obstacle. These include blind nasal intubation, 
awake or anaesthetized use of a flexible fiberoptic bronchoscope or laryngoscope as a guide, tracheostomy, or retrograde laryngeal intubation. There are drawbacks to all of these methods. Blind nasal intubations may result in life-threatening epistaxis, especially in patients who will be anticoagulated during cardiopulmonary bypass. Another adverse consequence in patients with significant cardiac disease is the increased risk of myocardial ischemia, resulting from tachycardia and hypertension which is common with nasal intubation or multiple laryngoscopies.

The use of flexible fiberoptic laryngoscopy for endotracheal intubation may also be difficult. First, after several attempts at laryngoscopy and intubation, secretions and oedema frequently impair adequate visualization, thereby decreasing the success rate. In addition, the operator attempting the intubation must be skilled in the use of this instrument, which must be readily available. Tracheostomy also has disadvantages which makes its use undesirable in open heart surgical patients. Foremost is an increased risk of bacterial contamination and infection of the sternotomy from the tracheostomy site.

Retrograde intubation was described in 1960 and subsequent modifications have been proposed. ${ }^{1-5}$ Retrograde tracheal guide placement was first reported by Butler and Cirillo' using a rubber catheter inserted via a tracheostomy. Criscothyroid membrane puncture was first reported by Waters ${ }^{2}$ who used a Huber-tipped Tuohy needle to pass an epidural catheter retrograde into the pharynx as a tracheal guide.

Patients undergoing cardiopulmonary bypass have an increased potential for bleeding as a result of impaired coagulation caused by heparinization, hyperfibrinolysis, dilution of clotting factors, ${ }^{6,7}$ and impaired platelet function. ${ }^{8,9}$ Because of this many anaesthetists have been hesitant to attempt retrograde intubation in patients undergoing open heart surgery for fear of tracheal bleeding or haemorrhage into peritracheal soft tissue as a result of the technique. In our series one patient did develop a small peritracheal haematoma, which was clinically insignificant. This was most likely the result of disseminated DIC which developed postoperatively. In no other patient was there any evidence of localized bleeding, i.e., haematoma, oozing from the puncture site, or blood obtained during suctioning of the endotracheal tube. Good oxygenation and ventilation, as assessed by blood gases, was further evidence that there was no impairment of pulmonary function as a result of this invasive approach. Tachycardia and hypertension, more common when using the multiple laryngoscopy approach, may result in increased myocardial oxygen demand, resulting in myocardial ischemia. Halothane or isoflurane were used in seven patients during Phase $A$ to prevent this untoward event. Some patients during Phase A had elevated ST segments which responded to nitroglycerin infusion and propranolol.

A 14-gauge puncture is not necessary, but we have found that the 16-gauge catheter can be maintained under greater tension so it was used in lieu of the 20-gauge epidural catheter.

Retrograde intubation can also be done while the patient is awake but under sedation. During this series one patient with chronic ankylosing spondylitis was intubated awake.

All the patients were intubated using a \#8 Portex (female) or a \#8.5 Portex (male) tube.

Retrograde intubation is not without complications. Perforation of the oesophagus and insertion of the tracheal tube through the perforation is possible. Infection at the puncture site is also a possibility. The technique requires skill and thorough knowledge of the anatomy of the neck. It should not be attempted by the novice.

Based on our experience, we feel that retrograde intubation is a safe alternate method for endotracheal intubation, even in patients who are going to be anticoagulated for CPB.

Acknowledgement

We thank Ms. Ellen L. Jackson for manuscript preparation.

\section{References}

1 Cirillo AA, Butler $F$. Retrograde tracheal intubation. Anesth Analg 1960; 39: 333-8.

2 Waters $D J$. Guided blind endotracheal intubation. Anaesthesia 1963; 18: 158-62.

3 Powell FW, Ozdil T. A translaryngeal guide for tracheal intubation. Anesth Analg 1967; 46: 231-4.

4 Bourke D, Levesque PR. Modification of retrograde guide for endotracheal intubation. Anesth Analg 1974; 53: 1013-4. 
5 Borland $L M$, Swan DM, Leff S. Difficult pediatric endotracheal intubation: a new approach to the retrograde technique. Anesthesiology $1981 ; 577-8$.

6 Tice D, Reed G, Clauss $R$, Worth $M$. Hemorrhage due to fibrinolysis occurring with open heart operations. J Thorac Cardiovasc Surg 1963; 46: 573-9.

7 Porter J, Silver D. Alterations in fibrinolysis and coagulation associated with cardiopulmonary bypass. J Thorac Cardiovasc Surg 1968; 56: 869-78.

8 Mielke $C H$, deLeral $M$, Hill JD, Macus $M$, Gerbodo $F$. Drug influence on platelet loss during extracorporeal circulation. J Thorac Cardiovasc Surg 1973; 66: 845-54.

9 Harker L, Malpass T, Branson H, Hesel E, Shachter $S$. Mechanism of abnormal bleeding in patients undergoing cardiopulmonary bypass: acquired transient platelet dysfunction associated with selective $\alpha$ granule release. Blood 1971; 56: 824-34.

\section{Résumé}

Les effets hémodynamiques lors a" une intubation difficile ont été étudiés sur 25 patients subissants une chirurgie à caur ouvert. Cette ếtude a été divisé en deux phases. La phase A comprend la période à partir de la première tentative de laryngoscopie jusqu'au quatrième échec de cette dernière; la phase $B$ débute après une période de stabilisation jusqu'à l' accomplissement d' une intubation rétrograde. Pendant la phase $A$ la fréquence cardiaque (HR) augmenta significativement de $75 \pm 6.5$ battements/min. avant laryngoscopie à $95 \pm 8.5$ ( $p<0.05)$ après la derniére laryngoscopie. La pression artérielle moyenne (MAP) augmenta de $82.5 \pm 4.75 \mathrm{mmHg} d$ $105 \pm 5.15(p<0.005)$ après la dernière laryngoscopie. $L$ 'index cardiaque $(\mathrm{Cl})$ diminua de $2.9 \pm 0.3 \mathrm{~L} \cdot \mathrm{min}^{-1}$. $m^{-2}$ avant la laryngoscopie a $2.55 \pm 0.15$ après la dernière tentative de laryngoscopie. La pression capillaire pulmonaire bloquée (PCWP) augmenta de $10.5 \pm L$ $\mathrm{mmHg}$ avant laryngoscopie a $19.15 \pm 1.5(p<0.01)$ après la derniere laryngoscopie tentative de laryngoscopie.

Aucun changement statistiquement significatif n'a été observé dans la fréquence cardiaque, tension artérielle moyenne, index cardiaque et pression capillaire pulmonaire bloquée avant et après intubation durant la phase $B$. Trois patients ont démontré une élévation du segment ST durant la phase A répondant à l'administration intraveineuse de nitroglycérine et de propranolol. Aucun changement du segment ST n'a été détecté durant la phase $B$. On observa des lacérations des lèvres er des bris de dents lors de la phase A. Un patient a développé un petit hématome péritrachéal après l'inlubation rétrograde pour lequel aucun traitement ne fut requis. Cette technique est sécure et produit des altérations hémodynamiques minimes lors d" une intubation difficile chez les patients subissants une chirurgie à cour ouvert. 